\title{
Macroscopic and Microscopic Mechanisms of Cement-Stabilized Soft Clay Mixed with Seawater by Adding Ultrafine Silica Fume
}

\author{
Qiang Li, Jie Chen, Qian Shi, and Shihao Zhao \\ Department of Civil Engineering, Zhejiang Ocean University, No. 1, South Haida Road, Changzhi Island, Lincheng Avenue, \\ Dinghai District, Zhoushan, Zhejiang 316022, China
}

Correspondence should be addressed to Qiang Li; qiangli_001@hotmail.com

Received 7 August 2014; Revised 20 October 2014; Accepted 21 October 2014; Published 13 November 2014

Academic Editor: Pavel Lejcek

Copyright (C) 2014 Qiang Li et al. This is an open access article distributed under the Creative Commons Attribution License, which permits unrestricted use, distribution, and reproduction in any medium, provided the original work is properly cited.

\begin{abstract}
The strength of the cement-stabilized soil can be improved by the use of seawater. Compressive strength test results show that the strength of cement-stabilized soil mixed with seawater is $50 \%$ greater than that mixed with freshwater at the 90th day. However, the application is limited because the expansion of the cement-stabilized soil mixed with seawater increases significantly. A kind of ultrafine silica fume was added into the cement-stabilized soil to inhibit swelling of the cement-stabilized soil with seawater. The expansion of cement-stabilized soil mixed with seawater by adding ultrafine silica fume is close to that of cement-stabilized soil mixed with freshwater. With the addition of ultrafine silica fume, the unconfined compressive strength increases by close to $6.5 \%$ compared with seawater alone at the 90th day. The mechanisms of adding ultrafine silica fume into the cement-stabilized soil mixed with seawater are revealed by several physical and chemical characterization parameters, such as specific gravity, unbound water content, surface morphology seen with SEM, and crystal products by X-ray diffraction tests. The results show that the crystal growth is an important factor, affecting the strength and expansion of cement-stabilized soil mixed with seawater.
\end{abstract}

\section{Introduction}

A commonly used method for soft soil reclamation is to mix cement or some other types of curing agents into the soil stratum. Unfortunately, the cured strength of traditional cementstabilized soft clay is low. In addition, in remote island locations, freshwater is in short supply and inconvenient to access. In such regions, the consumption of valuable freshwater resources for foundation reclamation may be difficult and seem somewhat wasteful. Some researches have shown that seawater may improve some physical and mechanical properties; for example, the unconfined compressive strength may be increased by approximately $20 \%$ [1]. Therefore, using seawater to mix cement with soft silty clay is preferable for island beach reclamation. Not only may it improve the strength of the cement-stabilized soil, but it also can conserve freshwater resources in remote island locales.

There have been some successful cases in which inorganic stabilizing materials have been applied to reclamation engineering in coastal regions. Studies have shown that the composition of the seawater originally contained in silty clay has a major impact on the curing of cement-stabilized soil from macroscopic and microscopic views. However, in these studies, simulated seawater or soil containing seawater ingredients formed by marine deposition was mixed with cement [2-5]. The direct use of seawater for mixing with cement and soft clay has been very rare. The main problem is that seawater contains large amounts of chloride ions, sulfate ions, magnesium ions, and other corrosive components, and all of these will affect the curing of the stabilized silty clay, the expansion, the strength, and even the durability of the mixture [6]. The mechanisms of expansion are attributed to formation of ettringite caused by the sulfate attack [7-10]. In fact, the ion composition of seawater has both negative and positive effects on the curing of stabilized soil. The right amount of ettringite produced by the chemical reactions of sulfate ions in seawater and stabilizer can improve the early strength of stabilized soil. For example, lime can be used as an admixture to improve the strength of soft marine soil, and its reinforcement mechanism has been proven to come from ettringite by means of several macroscopic and microscopic methods [11, 12]. However, this can also exacerbate sulfate 
TABLE 1: Typical physical parameters of soft silty clay at Zhoushan.

\begin{tabular}{cccccccccccc}
\hline & \multicolumn{4}{c}{ Physical parameters } & \multicolumn{3}{c}{ Consistency } & \multicolumn{3}{c}{ Soil classification } \\
\hline$w / \%$ & $G_{s}$ & $\begin{array}{c}\rho \\
\mathrm{g} / \mathrm{cm}^{3}\end{array}$ & $\begin{array}{c}\rho_{d} \\
\mathrm{~g} / \mathrm{cm}^{3}\end{array}$ & $S_{r} / \%$ & $e$ & $w_{L} / \%$ & $w_{p} / \%$ & $I_{p}$ & $I_{L}$ & Hardness & Classification \\
\hline 35.98 & 2.72 & 1.88 & 1.38 & 100.0 & 0.97 & 37.68 & 21.95 & 15.73 & 0.89 & Soft plastic & Soft silty clay \\
\hline
\end{tabular}

Note: $w$ denotes moisture content, $G_{s}$ denotes specific density, $\rho$ denotes natural density, $\rho_{d}$ denotes dry density, $S_{r}$ denotes saturation, $e$ denotes void ratio, $w_{L}$ denotes liquid limit, $w_{p}$ denotes plastic limit, $I_{p}$ denotes plasticity index, and $I_{L}$ denotes liquidity index. All the parameters were obtained from rigorous tests provided by China standard for soil test method (GB/T 50123-1999). The soil classification was classified according to the code for the design of building foundation (GB 50007-2011).

TABLE 2: Ion analysis of three water sources.

\begin{tabular}{lcccccc}
\hline Water sources & \multicolumn{3}{c}{ Cations (mg/L) } & \multicolumn{3}{c}{ Anions (mg/L) } \\
& $\mathrm{Ca}^{2+}$ & $\mathrm{Mg}^{2+}$ & $\mathrm{Na}^{+}+\mathrm{K}^{+}$ & $\mathrm{Cl}^{-}$ & $\mathrm{SO}_{4}{ }^{2-}$ & $\mathrm{HCO}_{3}^{-}$ \\
\hline Freshwater & 8.04 & 8.40 & 210.50 & 12.10 & 53.20 & 89.40 \\
Soil water & 12.38 & 93.00 & 556.90 & 689.40 & 136.30 & 110.70 \\
Seawater & 188.20 & 2300.00 & 6287.60 & 16000.00 & 2196.48 & 7.1 \\
\hline
\end{tabular}

attack and cause expansion damage of stabilized soil. To address the problem of sulfate attack, it is necessary to adopt effective preventive measures to avoid expansion caused by excessive ettringite produced in the course of hydration. Adding fly ash, silica fume or blast furnace slag into limestabilized soil can limit the sulfate-heave effectively [13-16]. A method of preventing the erosion of cement-stabilized soil from seawater has also been proposed by adding amorphous silica fume into cement-stabilized soil [17]. In this paper, three samples with different ratios of silica fume are illustrated; however, its results are still based on marine deposition rather than directly on seawater. A method that improved the alkaline environment of marine deposits by adding industrial caustic soda to cement-stabilized soil to inhibit the formation of ettringite and increase the content of calcium silicate hydrate gel was adopted in China but resulted in soil that was strongly alkaline [18]. The above-mentioned cases suggest that ions in seawater can play a positive role in soil curing and reclamation. However, it is important to ensure how it works for the cement-stabilized soil mixed with seawater and identify the relations between macroscopic and microscopic parameters by means of experimental methods.

In this paper, the seawater-cement slurry was mixed into the soil. Due to the complex composition of seawater and its high ion content, the cement-stabilized soil directly mixed with seawater will exhibit two tendencies: on one hand, the strength of the cement-stabilized soil is improved by the use of seawater; on the other hand, the expansion of the cementstabilized soil increases significantly. The mechanisms of strength development and expansion were studied by experimental methods, with the goal of identifying an appropriate admixture to control the expansion of the cement-stabilized soil mixed with seawater so that seawater resources can be used for soil reclamation purposes.

\section{Materials and Methods}

2.1. Materials and Preparation. In our experiments, an admixture was added into soil samples taken from the foundation pit of a project in Zhoushan city. The traditional experimental tests were performed to obtain the basic physical and consistency parameters of the clay, as shown in Table 1. The admixture is composed of cement and silica fume. The proportion of the weight of admixture and soil is $15 \%$. The ratio of silica fume and cement is $1: 4$. The ratio of water and cement is 0.5 . Firstly, we blended the cement and admixture with the predetermined proportion. Then, we added water into the mixtures to make a slurry. Finally, the mixtures were added into the soil and stirred evenly.

The water for ion analysis came from three water sources, namely, freshwater, seawater, and the water in the soil. The seawater was taken from the coastline of Dinghai Harbor. The water in the soil was extracted from the soil samples using an extraction method that adheres strictly to the provisions of the standard test method. Ion analysis of the different water sources revealed that the anion and cation contents in seawater were more than an order of magnitude greater than those of the soil water, and those of the freshwater were lower than those of the soil water, as shown in Table 2. Therefore, mixing seawater with cement-stabilized soil had a significant impact on ion exchange.

Portland cement labeled P.C 32.5 from Anhui $\mathrm{CONCH}$ cement Co., Ltd. (Anhui, China) was used in this research. The ultrafine silica fume used in this research was obtained from Chengdu Huiye Materials Co., Ltd (Chengdu, China). The fineness of the ultrafine silica fume is between 0.1 and $0.2 \mu \mathrm{m}$, the content of amorphous $\mathrm{SiO}_{2}$ is greater than $95 \%$, and it includes other constituents that are $\mathrm{Fe}_{2} \mathrm{O}_{3}, \mathrm{Al}_{2} \mathrm{O}_{3}, \mathrm{CaO}$, $\mathrm{K}_{2} \mathrm{O}, \mathrm{Na}_{2} \mathrm{O}, \mathrm{MgO}$, and $\mathrm{C}$, as shown in Table 3. XRD patterns of silica fume are shown in Figure 1. It can be observed that the ultrafine silica fume exhibits the XRD pattern of the amorphous state.

For unconfined compressive strength testing, cementstabilized clay samples blended with cement slurry were remolded into specimens $39.1 \mathrm{~mm}$ in diameter and $80 \mathrm{~mm}$ in height. The samples were then tamped by layer, generally three times, with the most uniform tamp strength possible. The density of the soil samples was approximately $1.92 \mathrm{~g} / \mathrm{cm}^{3}$, which was a litter bigger than original soil samples. The 
TABle 3: Composition of silica fume (\%).

\begin{tabular}{lcccccccc}
\hline Ingredients & $\mathrm{SiO}_{2}$ & $\mathrm{Fe}_{2} \mathrm{O}_{3}$ & $\mathrm{Al}_{2} \mathrm{O}_{3}$ & $\mathrm{CaO}$ & $\mathrm{K}_{2} \mathrm{O}$ & $\mathrm{Na}_{2} \mathrm{O}$ & $\mathrm{MgO}$ & $\mathrm{C}$ \\
\hline Content (\%) & 95.20 & 2.10 & 1.85 & 0.41 & 0.29 & 0.08 & 0.05 & 0.02 \\
\hline
\end{tabular}

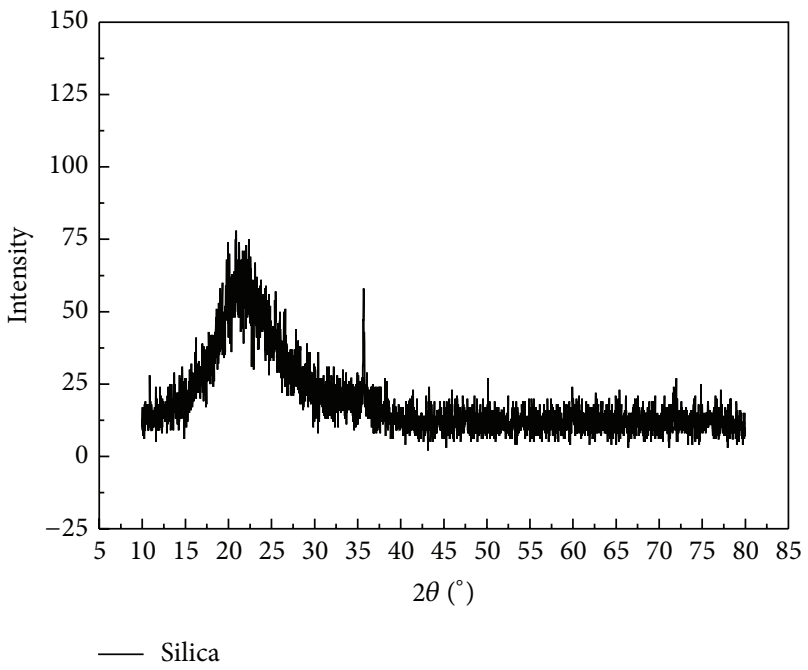

FIGURE 1: XRD patterns of ultrafine silica fume.

specimens for the strength tests were wrapped with a plastic film and immediately placed into a temperature and humidity-controlled chamber. The samples for each different formulation were divided into three groups for testing at different curing ages, and the averages of the test results were determined for each curing age.

For expansion testing, these samples of the same mixtures were formed into specimens with an area of $30 \mathrm{~mm}^{2}$ and a height of $20 \mathrm{~mm}$. The expansion samples were mounted into the dilatometer and maintained in an indoor environment at a constant temperature during the testing process.

The specific gravity tests and XRD tests required samples of powder. The finer fractions of the samples were finely powdered in an agate mortar. The particles of the samples that pass through the \#325-mesh sieve were retained for further tests.

2.2. Experimental Methods and Instruments. Various experiments, including physical and chemical tests, were performed to study the properties of cement-stabilized soil mixed with seawater on both the macroscopic and microscopic scales. One admixture of ultrafine silica fume was added to the cement slurry to inhibit swelling and improve the strength of the cement-stabilized soil mixed with the seawater. The main procedures followed in those experiments are described below.

Ion analysis provides the basic data for the analysis of ion reactions and mineral formation reactions. A titration apparatus was used to test the ions in the seawater and the soil extract.

A series of swelling experiments were conducted using an expansion apparatus. There are two kinds of expansion tests, one is load-free test and the other is underload test.
Expansion tests were conducted in soil bins of odometers filled with water, which can restrain radial deformation and make the soil sample swell vertically. The water is $5 \mathrm{~mm}$ above the top surface of the soil. Expansion values were measured by micrometer with dial indicator. The dial gauge was checked for changes at specific time intervals to monitor expansion, and then the expansion rate can be converted through a formula. The expansions of samples of the cement-stabilized soil mixed with freshwater and seawater were compared at different curing ages to verify whether the cement-stabilized soil mixed with seawater would exhibit greater expansion and whether that expansion could be controlled by using admixtures.

Using the oven drying method, moisture content was measured at different curing ages and reflected the water losses of the cement-stabilized soil at $105^{\circ} \mathrm{C}$. The results can be used to make inferences about the crystallinity of the cementstabilized soil.

Compressive strength experiments were performed using an unconfined compressive strength apparatus. Uniaxial compressive strengths of cement-stabilized soils with different mixture ratios and at different curing ages were obtained from the unconfined compressive strength test.

$\mathrm{X}$-ray diffraction (XRD) analysis was performed using an XRD system "DX-2700" with a Cu target. The results of this analysis were used to verify the crystal products of the hydration process of cement-stabilized soil. Together with the expansion tests, the moisture content tests, and the strength tests, crystal production with curing age was studied to illustrate the effects of the generation of minerals on the properties of cement-stabilized soil mixed with seawater.

Scanning electron microscopy (SEM) was used to obtain information on the fracture surface morphology of cementstabilized soil samples at different ages using a ZEISS apparatus "SUPRA 55." The structures and main hydration products of the cement-stabilized soil were studied to find direct evidence of crystal generation in the process of hydration of the cement-stabilized soil.

\section{Experimental Results and Analysis}

3.1. Compressive Strength Tests. The unconfined compressive strength of a cement-stabilized soil is obtained by using the unconfined compressive strength test method referred to standard for soil test method (GB/T 50123-1999). Figure 2 shows the changes in the unconfined compressive strength of cement-stabilized soil with age under different mixing conditions. It can be observed that the compressive strength of cement-stabilized soil increases rapidly with increasing curing age before 28 days, and then the strength increases continuously to 90 days, but the increasing ratio of strength decreases. The strength of cement-stabilized soil mixed with seawater is $50 \%$ greater at the 90 th day than that mixed 


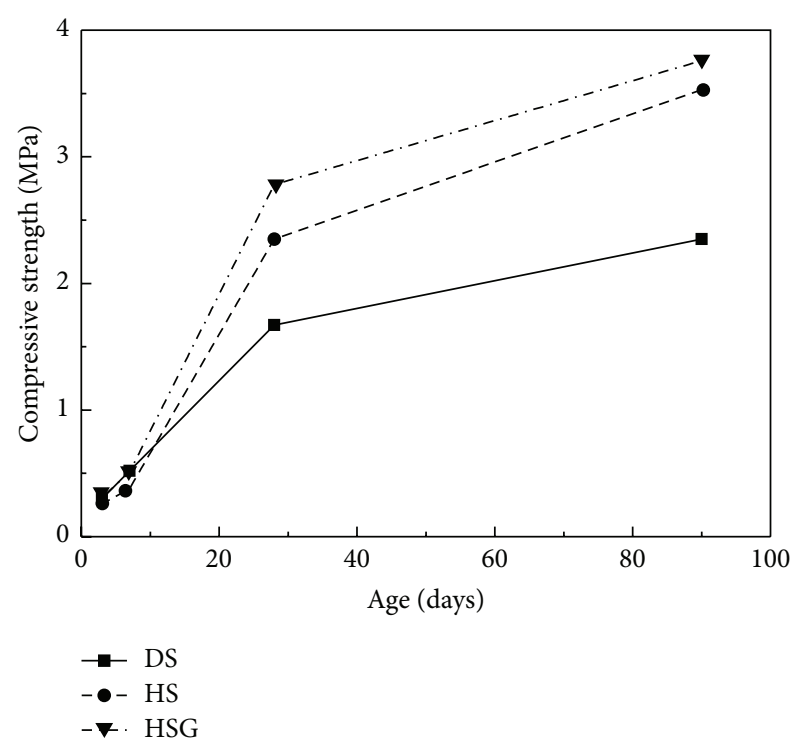

FIGURE 2: Effects of curing age on unconfined compressive strength of cement-stabilized soils. DS: cement-stabilized soil mixed with freshwater; HS: cement-stabilized soil mixed with seawater; HSG: cement-stabilized soil with seawater and added silica fume.

with freshwater, and the addition of ultrafine silica fume further improves the strength by close to $6.5 \%$ compared with seawater alone.

There are two kinds of reasons for explaining the mechanism of strength increase. Firstly, the compactness of cementstabilized soil increases with the increasing curing age in the course of hydration. The addition of ultrafine admixture also increases the compactness. Secondly, the crystals of cement-stabilized soil strengthened the structure of soil [1921]. Figure 3 shows the image of the surface topography of cemented soil mixing with seawater and without silica fume under the scanning electron microscope (SEM) at the 7th day and the 90th day. There are three different magnifications, that is, $500 \mathrm{x}, 3000 \mathrm{x}$, and $7000 \mathrm{x}$. It is shown that the surface morphology is similar at two curing ages, but the surface is more dense at the 90th day than the one at the 7 th day. In the higher magnification, the crystal growth can be found that the crystals at the 7th day are smaller and look like acicular, and, after 90 days, crystalline substance looks like columnar obviously. Figure 4 shows images of the surface topography of clay, cement-stabilized soil mixed with freshwater and cement-stabilized soil mixed with seawater with and without the addition of ultrafine silica under SEM. The surface morphology is different under the four cases, with the addition of silica resulting in a denser surface after 28 days. It could be identified that the surface without silica fume developed some microcracks, but with the addition of silica fume it was filled with some stuff.

3.2. Expansive Experiment. Expansion is a significant parameter reflecting the swelling nature of soil. The nonloaded and loaded swelling tests are as shown in Figure 5. Several loads were applied on the top of samples with $0 \mathrm{kPa}, 1.25 \mathrm{kPa}$,
$4.5 \mathrm{kPa}$, and $12.5 \mathrm{kPa}$. Four groups of samples with watercement ratios of 0.5 and total contents of cementitious materials of $15 \%$ are tested: the original soil, cement-stabilized soil mixed with freshwater, cement-stabilized soil mixed with seawater, and cement-stabilized soil mixed with seawater and silica fume (at a ratio of silica fume to cement of 1:4). The results from those experiments show that the natural soil used in this test exhibits no swelling and the expansion of the cement-stabilized soils with various admixtures can be limited under a sufficiently high pressure (e.g., $12.5 \mathrm{kPa}$ ).

Figure 6 shows that the load-free expansion of cementstabilized soil mixed with freshwater exhibits a clear double plateau during a 90-day test, increasing rapidly at the initial stage, becoming flat after 7 days and remaining flat for several days, increasing again up to 28 days, and undergoing another plateau again after 49 days. The total expansion is up to $0.65 \%$. However, the expansion of cement-stabilized soil mixed with seawater does not plateau but rather continues to increase and in 90 days reaches $1.69 \%$. The results show that the expansion of cement-stabilized soil mixed with seawater is uncontrolled, and direct mixing with seawater is thus hazardous to the project. The results of swelling experiments on cement-stabilized soil mixed with ultrafine silica fume under several different pressures are also shown in Figure 6. The load-free expansion of cement-stabilized soil mixed with seawater with added silica fume is lower than that with seawater alone. Its expansion rate is less than $0.75 \%$ over 90 days, which is close to that measured for the mix containing freshwater. The expansion trends under different loadings are essentially similar, but the expansion rate decreases rapidly with the increasing pressure. The unloading expansion of cement-stabilized soil mixed with seawater and admixture exhibits multilevel plateaus, indicating that crystallization in the cement-stabilized soil changes in stages during the curing process.

3.3. Macroscopic and Microscopic Physical Characterization of Cement-Stabilized Soil. Traditionally, the main cause of swelling damage in cement-stabilized soil is viewed as the growth of ettringite. There are two theories for explaining the damaging effects of ettringite: the colloidal expansion theory and the crystal growth theory [22]. In this paper, the following three physical indicators of crystal growth in cement-stabilized soil mixed with seawater and admixtures are illustrated. It can be shown that the crystal growth theory can reveal the microscopic properties of cement-stabilized silty clay mixed with seawater.

3.3.1. Physical Characterization of Crystal Growth: Specific Gravity. When cement is mixed with water and agitated with silty clay, the soil gradually solidifies as the hydration of the cement proceeds and cementation with the soil particles occurs, accompanied by the continuous generation and growth of crystals. The specific gravities of the cement, silica fume, and silty clay used in this study are 3.1, 2.2, and 2.72, respectively. The specific gravity of the clay changes after it is mixed with cement. Figure 7 shows the specific gravities of the three cement-stabilized soils mixed with freshwater, 

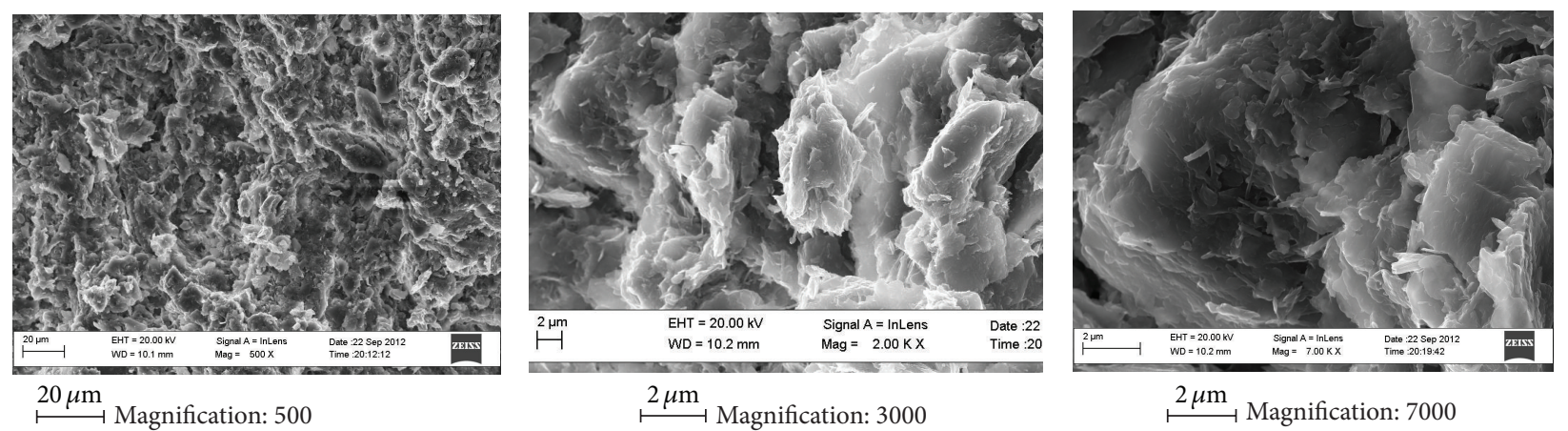

(a) At the 7th day
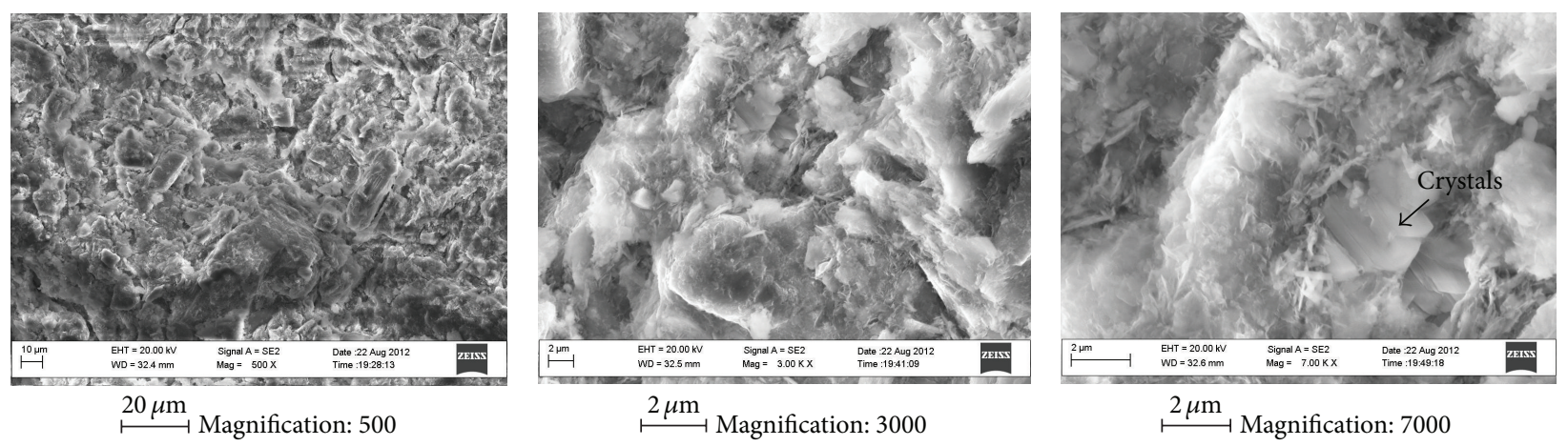

(b) At the 90th day

FIGURE 3: SEM of cemented soil with seawater (without silica fume) at different magnifications after curing.

seawater, and seawater adding ultrafine silica at different curing ages. The specific gravity of the different cementstabilized soils exhibits a decreasing trend with curing age. In the initial stage of curing, the specific gravity declines more rapidly but gradually stabilizes later. The specific gravity of the cement-stabilized soil mixed with seawater is the lowest at the 90th day. This result indicates that the crystal growth in cement-stabilized soil mixed with seawater is more ample than that in other soil mixtures, and this is consistent with the expansion test results for cement-stabilized soil mixed with seawater. This phenomenon reflects the fact that the specific gravity declines with the formation of hydration products and the growth of crystals due to the smaller contributions of the hydration products and crystals to the specific gravity. For example, the specific gravities of $\mathrm{CSH}, \mathrm{CH}, \mathrm{AFt}$, and $\mathrm{AFm}$ are $2.0,2.2,1.75$, and 1.95 , respectively (CSH: hydrated calcium silicate; $\mathrm{CH}$ : calcium hydroxide; Aft: ettringite; AFm: single sulfur calcium sulphoaluminate).

\subsubsection{Physical Characterization of Crystal Growth: Moisture} Content in terms of Unbound Water. Generally, the moisture content of cement-stabilized soil gradually decreases with curing age. The hydrated reaction of cement-stabilized soil can be expressed as follows:

$$
\begin{aligned}
& 3 \mathrm{CaO} \cdot \mathrm{SiO}_{2}+n \mathrm{H}_{2} \mathrm{O} \\
& \quad=x \mathrm{CaO} \cdot \mathrm{SiO}_{2} \cdot y \mathrm{H}_{2} \mathrm{O}+(3-x) \mathrm{Ca}(\mathrm{OH})_{2}
\end{aligned}
$$

$$
\begin{aligned}
& 2 \mathrm{CaO} \cdot \mathrm{SiO}_{2}+n \mathrm{H}_{2} \mathrm{O} \\
& \quad=x \mathrm{CaO} \cdot \mathrm{SiO}_{2} \cdot y \mathrm{H}_{2} \mathrm{O}+(2-x) \mathrm{Ca}(\mathrm{OH})_{2} \\
& 4 \mathrm{CaO} \cdot \mathrm{Al}_{2} \mathrm{O}_{3} \cdot \mathrm{Fe}_{2} \mathrm{O}_{3}+7 \mathrm{H}_{2} \mathrm{O} \\
& \quad=3 \mathrm{CaO} \cdot \mathrm{Al}_{2} \mathrm{O}_{3} \cdot 6 \mathrm{H}_{2} \mathrm{O}+\mathrm{CaO} \cdot \mathrm{Fe}_{2} \mathrm{O}_{3} \cdot \mathrm{H}_{2} \mathrm{O} \\
& 3 \mathrm{CaO} \cdot \mathrm{Al}_{2} \mathrm{O}_{3}+3\left(\mathrm{CaSO}_{4} \cdot 2 \mathrm{H}_{2} \mathrm{O}\right)+(24 \sim 26) \mathrm{H}_{2} \mathrm{O} \\
& \quad=3 \mathrm{CaO} \cdot \mathrm{Al}_{2} \mathrm{O}_{3} \cdot 3 \mathrm{CaSO}_{4} \cdot(30 \sim 32) \mathrm{H}_{2} \mathrm{O} \\
& 3 \mathrm{CaO} \cdot \mathrm{Al}_{2} \mathrm{O}_{3} \cdot 3 \mathrm{CaSO}_{4} \cdot 32 \mathrm{H}_{2} \mathrm{O}+2\left(3 \mathrm{CaO} \cdot \mathrm{Al}_{2} \mathrm{O}_{3}\right) \\
& \quad+4 \mathrm{H}_{2} \mathrm{O}=3\left(3 \mathrm{CaO} \cdot \mathrm{Al}_{2} \mathrm{O}_{3}\right) \cdot \mathrm{CaSO}_{4} \cdot 12 \mathrm{H}_{2} \mathrm{O}
\end{aligned}
$$

In those reactions, unbound water is consumed to form various crystal products. The moisture content decreases more rapidly during the initial stage of curing because the degree of crystallinity of the cement-stabilized soil increases rapidly during the initial stage of curing, which reduces the unbound water in the cement-stabilized soil. Then, the moisture content gradually becomes stable at approximately the 7 th day, and, after 28 days, it declines again. Figure 8 shows that the moisture content of cement-stabilized soil mixed with seawater and added with and without silica fume appears to reach a middle platform at curing age of 14 to 28 days. This platform may occur at a transition phase of the gel and the crystal, in which the moisture of the gel is easily evaporated at the test temperature of $105^{\circ} \mathrm{C}$. The changes 

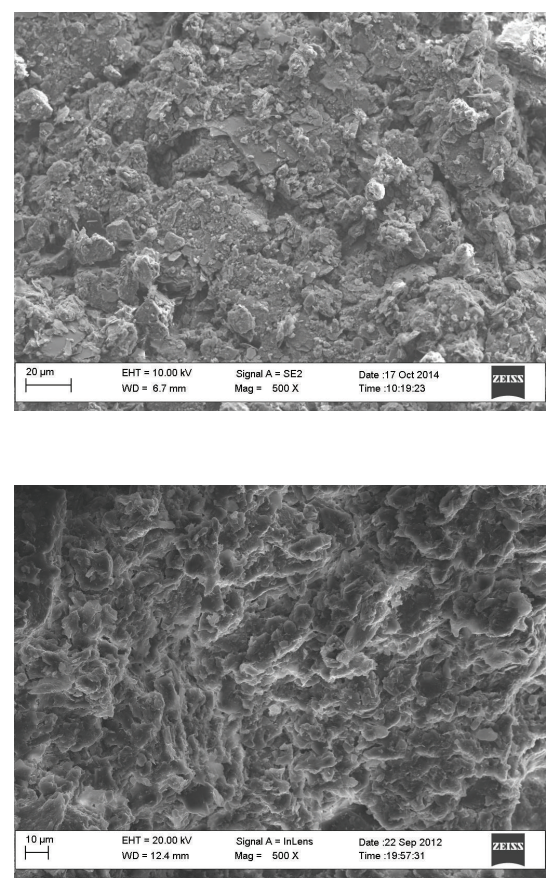

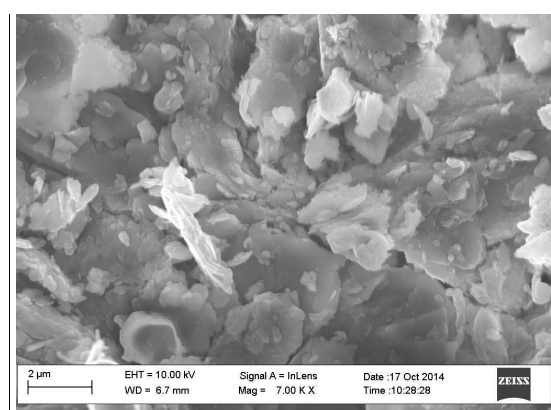

(a) Silty clay
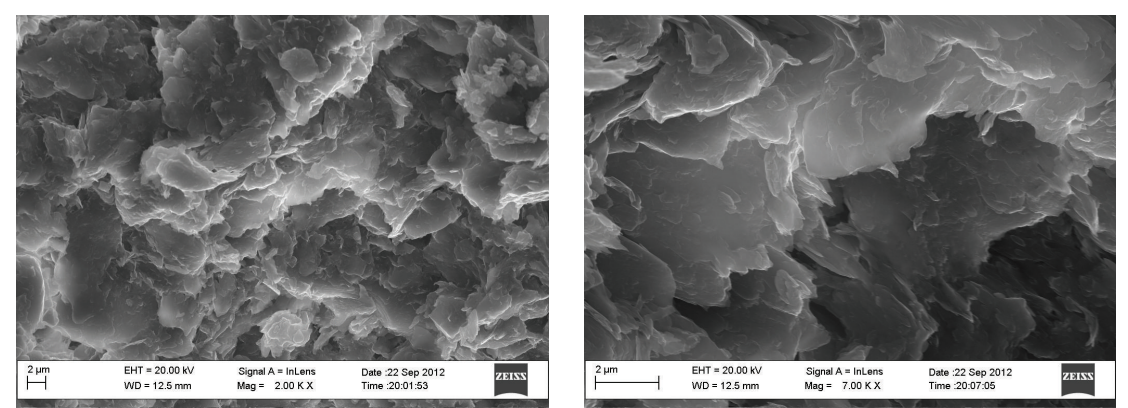

(b) Freshwater mixing cemented soil without silicon at the 28th day
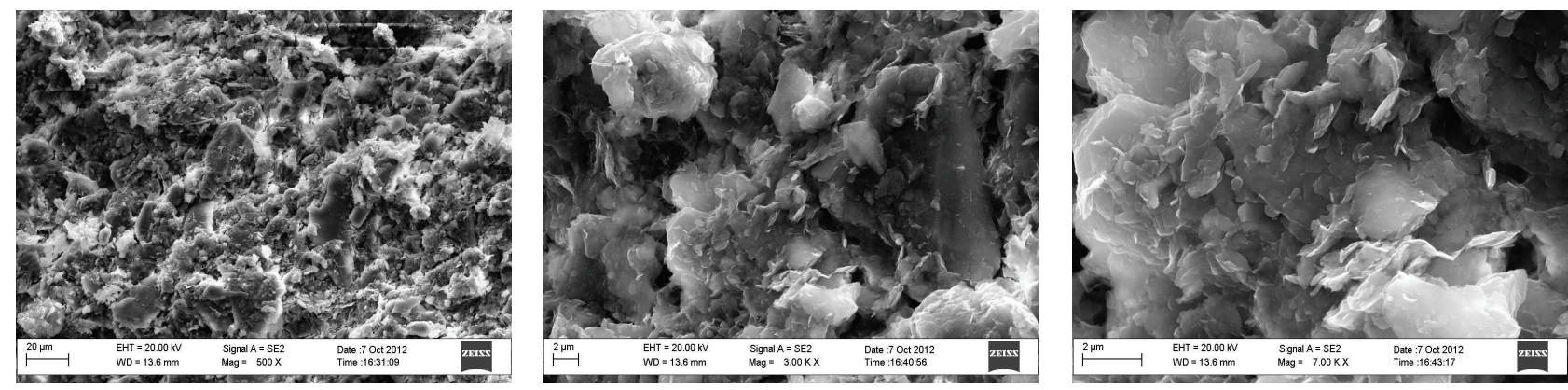

(c) Seawater mixing cemented soil without silicon at the 28 th day
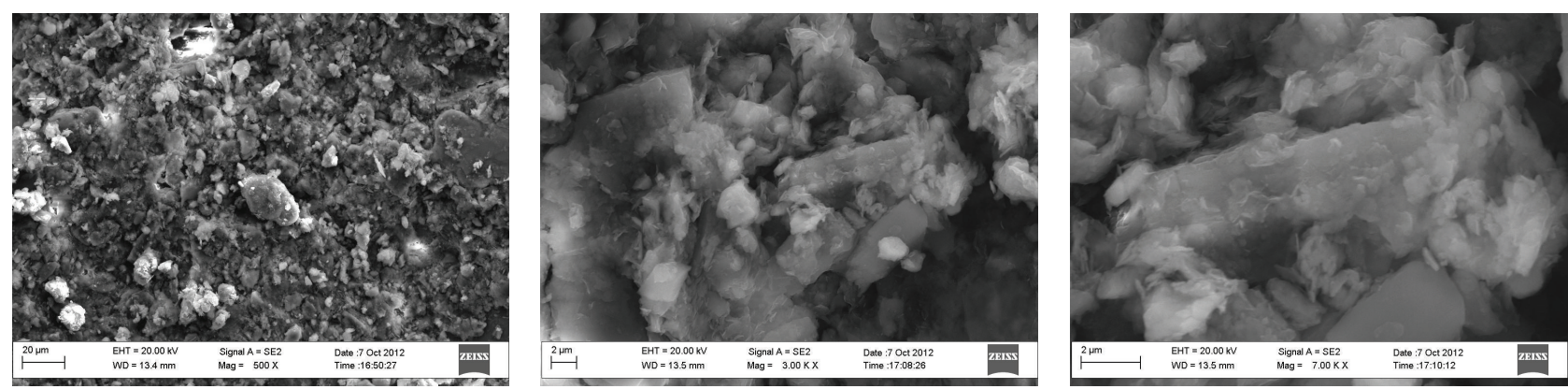

(d) Seawater mixing cemented soil with ultrafine silicon at the 28th day

FIgURE 4: Surface morphology of cemented soil under SEM.

in the moisture content of the cement-stabilized soil mixed with seawater are not obvious. The moisture content curves suggest that the moisture content of cement-stabilized soil mixed with silica fume and seawater is the highest at the 90th day, which indicates that water is not lost as easily when silica fume is used as an admixture because of the denser pore structure created.
3.3.3. Physical Characterization of Crystal Growth: Surface Morphology by Using SEM. As shown in Figure 4, at high magnification, the crystal structures of cement-stabilized soil mixed with seawater with and without the addition of ultrafine silica can be observed after 28 days. The crystals of the cement-stabilized soil without added silica are flaky; however, the presence of larger and columnar crystalline 


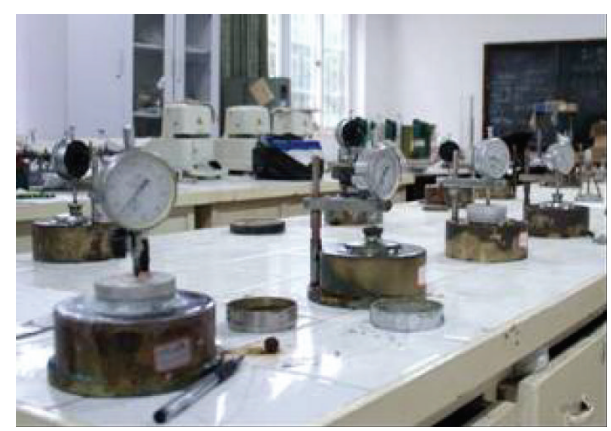

(a)

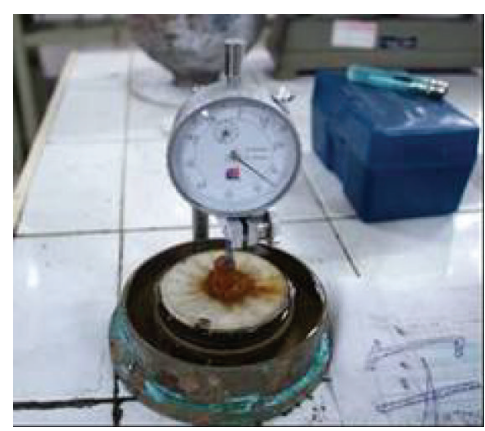

(b)

FIGURE 5: Loaded and load-free expansion experiments.

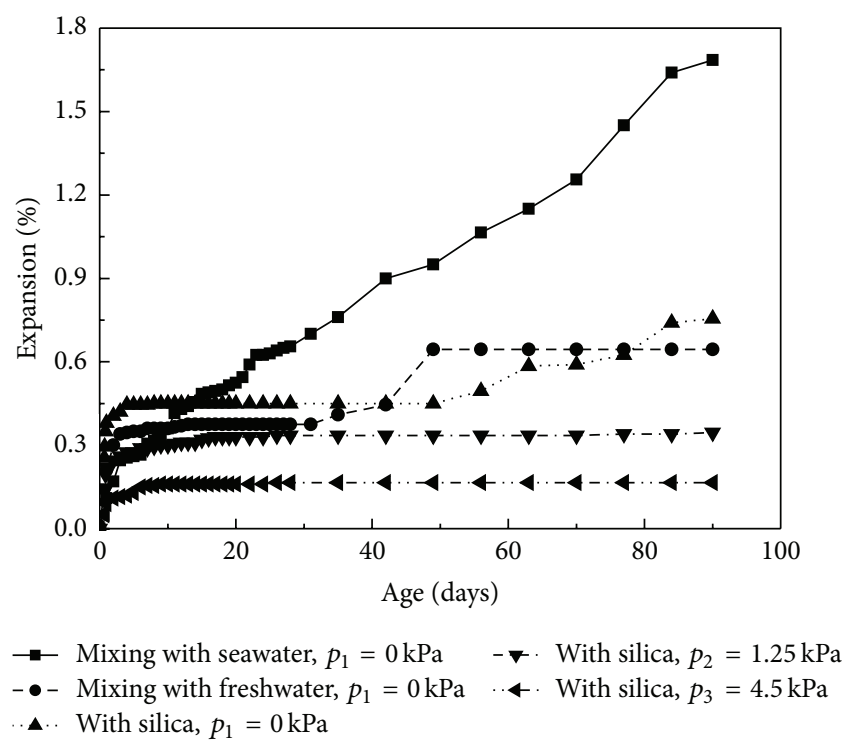

FIGURE 6: Comparison of the expansion for several cementstabilized soils.

substances is obvious in the cement-stabilized soil with added silica.

From the above-mentioned, we can find that the crystal growth is an important factor, affecting the strength and expansion of cement-stabilized soil mixed with seawater.

\subsection{Chemical Characterization of Cement-Stabilized Soil:} XRD Pattern. The strength of cement stabilized soil mixed with seawater is obviously greater than that mixed with freshwater. However the expansion of the former is also greater than the latter. Utilizing ultrafine silica fume as an admixture can better control the cement soil expansion and further enhance the strength. In the last section, we determined that these changes in physical properties were related to the crystal growth generated by cement soil hydration. In this section, the mechanisms are further indicated by chemical characterization through the XRD method.

From the XRD test, as shown in Figure 9, we can see that the hydration products such as hydrated calcium silicate,

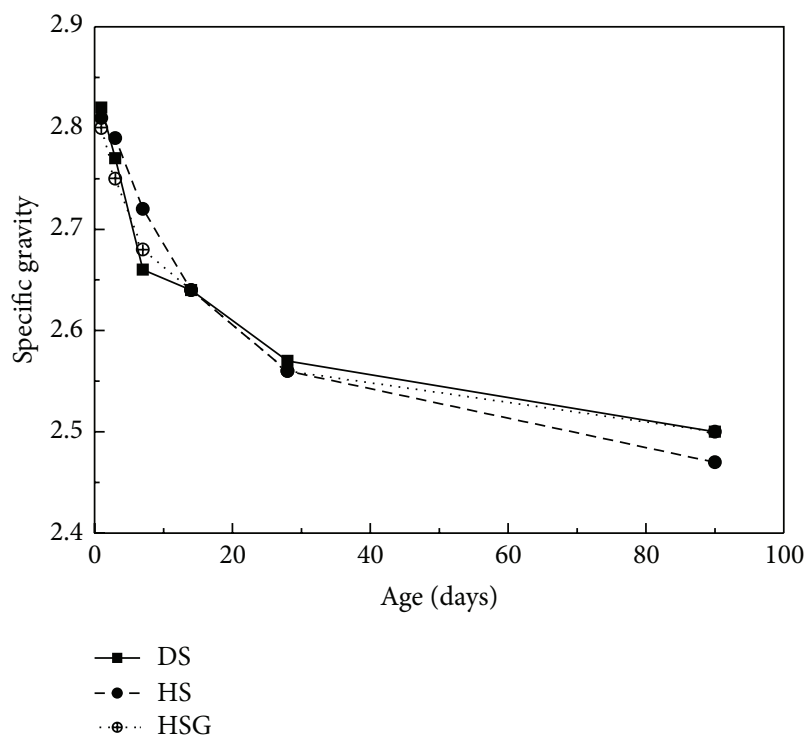

FIGURE 7: Specific gravity of cement-stabilized soil with seawater at different curing ages. DS: cement-stabilized soil mixed with freshwater; HS: cement-stabilized soil mixed with seawater; HSG: cement-stabilized soil with seawater and added silica fume.

calcium aluminosilicate, and hydrated andradite increase significantly during hydration, indicating that crystallization increases with curing age. It can also be shown that despite the similarities between crystals of cement-stabilized soil mixed with freshwater and seawater, there is something different. In the early hydration (the first day) of cement-stabilized soil, the concentration of crystallization products in the cementstabilized soil mixed with freshwater is significantly greater than that in the cement-stabilized soil mixed with seawater. This might be the high salt content of seawater inhibiting the formation of CSAH. Up to the 7th day, the concentrations of hydration products in the two types of cement-stabilized soil are relatively close. After 28 days, although the cementstabilized soil mixed with freshwater still contains more hydrated calcium aluminosilicate, the cement-stabilized soil mixed with seawater contains more hydrated calcium silicate than the former. These trends are consistent with the results of the expansion, specific gravity, and compressive strength 


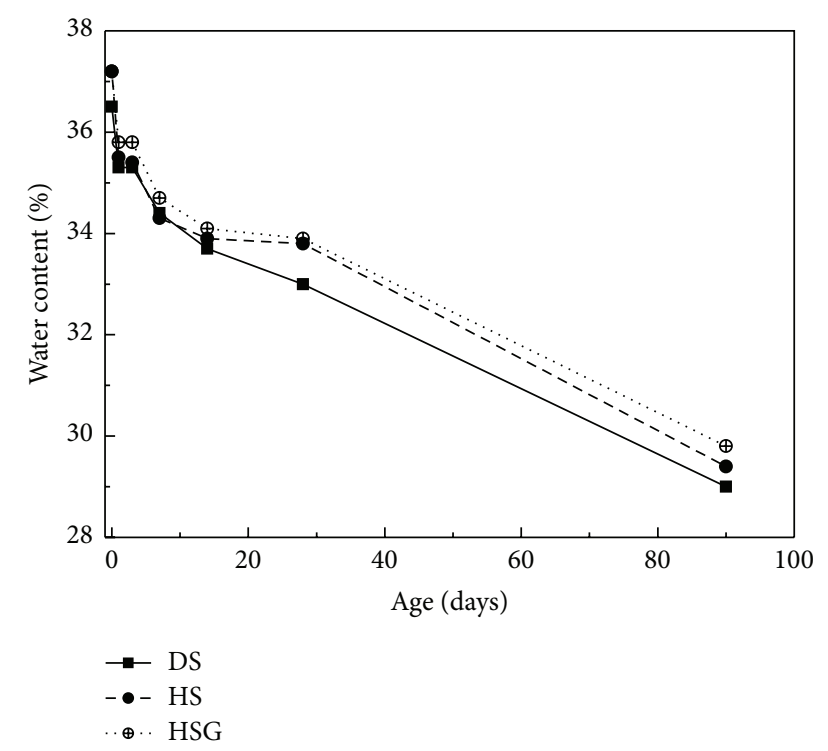

FIGURE 8: Moisture content (unbound water) of cement-stabilized soil at different curing ages. DS: cement-stabilized soil mixed with freshwater; HS: cement-stabilized soil mixed with seawater; HSG: cement-stabilized soil with seawater and added silica fume.

tests. For example, the expansion of the cement-stabilized soil mixed with seawater is less than that of the cementstabilized soil mixed with freshwater in the first 7 days, after which the expansion of the former exceeds that of the latter. The decrease rate of the specific gravity of the cement-stabilized soil mixed with seawater is slower than that of freshwater in the first 7 days, which indicates a slower crystallization rate in the latter. After 7 days, the decrease rate of the specific gravity of the cement-stabilized soil mixed with seawater exceeds that of the cement-stabilized soil mixed with freshwater. Comparing the compressive strength in Figure 2, it also can be shown that the compressive strength of the cement soil mixed with seawater is lower than that of the freshwater at the 3rd day and the 7th day; however, at the 28th day, the compressive strength of the cement soil mixed with seawater is greater than that of the freshwater. These phenomena demonstrate that mixing with seawater weakens early hydration but strengthens later hydration.

Figure 10 shows that ultrafine silica fume can consume the calcium ions in the system; thus, the ion exchange of the cement-stabilized soil and the crystals is reduced and expansion can be controlled. However, the use of silica fume improves the strength of cement-stabilized soil further because silica fume particles are small and highly active, which enhances their pozzolanic effects and cementation effects, resulting in the filling of pores and improved density. By comparing the XRD patterns of cement-stabilized soil with seawater in varying ages, it can be seen that the diffraction peak gradually decreases with the growth of curing time for the samples with ultrafine silica fume added while the other one with nothing blended behaves inversely. The hydration products of cement-stabilized soil mixed with seawater with added ultrafine silica fume at the initial stage show a higher diffraction, and as curing time is growing, the hydration crystals generation lags behind the cement soil without silica fume, but in both cases, the diffraction intensity remains the same after 28 days.

\section{Discussion}

From a macropoint of view, it has two effects when using seawater as the mixing water of cement soil. One is enhancing the strength of cement soil at the 28th day to some extent and the other is increasing its expansion dramatically. However, this expansion might cause cement soil cracking, affecting the long-term strength and confining its application in engineering. Adding silica fume into cement-stabilized soil mixed with seawater has two effects: one suppresses the expansion of seawater soil cement and the second is to further improve the strength of cement-stabilized soil. The two effects may be attributed to the three reasons illustrated as follows: pozzolanic effect, filling effect, and antierosion, all of which can overcome the adverse effects lead by using seawater alone and consequently enable cement soil mixed with seawater to be applied to practical projects. In this section, the mechanism of cement-stabilized soil mixed with seawater by adding ultrafine silica fume will be discussed in detail.

4.1. Pozzolanic Effect. After the incorporation of the cement hydration reaction, it produced high alkaline calcium silicate hydrate and slaked lime. When adding a certain proportion of silica, the active silica reacts with slaked lime and hydrated calcium silicate to give the pozzolanic reaction consuming the slaked lime while improving the quality of gelatinization crystals of hydrated calcium silicate. By comparing the XRD patterns of cement-stabilized soil with seawater in varying ages, it can be seen that the diffraction peak (the highest diffraction peak corresponds to two crystals: $\mathrm{SiO}_{2}$ and hydrated calcium silicate; the second peak corresponds to two crystals also: $\mathrm{SiO}_{2}$ and hydrated calcium aluminosilicate) gradually increases with the growth of curing time for the samples without ultrafine silica fume, while the other one with that blended behaves inversely for the first peak but keeps the second peak stable. The phenomenon occurs because when being mixed without silica fume, the cement and the $\mathrm{SiO}_{2}$ contained in the original soil gradually participate in the hydration then generate the crystals of hydrated calcium silicate and hydrated calcium aluminosilicate, which outstrips the consumption of $\mathrm{SiO}_{2}$, consequently showing the growing trend of the highest diffraction peak. However, adding activated silica fume into cement-stabilized soil mixed with seawater promotes the early hydration products at the initial period of cement hydration, resulting in the fact that the content in early hydrated calcium silicate (XRD studies show that calcium silicate hydrate crystals are $\mathrm{Ca}_{2} \mathrm{SiO}_{4} \cdot 0.35 \mathrm{H}_{2} \mathrm{O}$ with a calcium silicon ratio $\mathrm{C} / \mathrm{S}=$ $2>1.5$, which belongs to a high alkaline calcium silicate hydrate) and hydrated calcium aluminosilicate (also known as gismondine, $\mathrm{CaO} \cdot \mathrm{Al}_{2} \mathrm{O}_{3} \cdot 2 \mathrm{SiO}_{2} \cdot 4 \mathrm{H}_{2} \mathrm{O}$ ) is being higher and exhibiting high diffraction peaks. Nevertheless, as hydration continues, high alkaline hydrated calcium silicate converts into low alkaline hydrated calcium silicate, and $\mathrm{SiO}_{2}$ and 

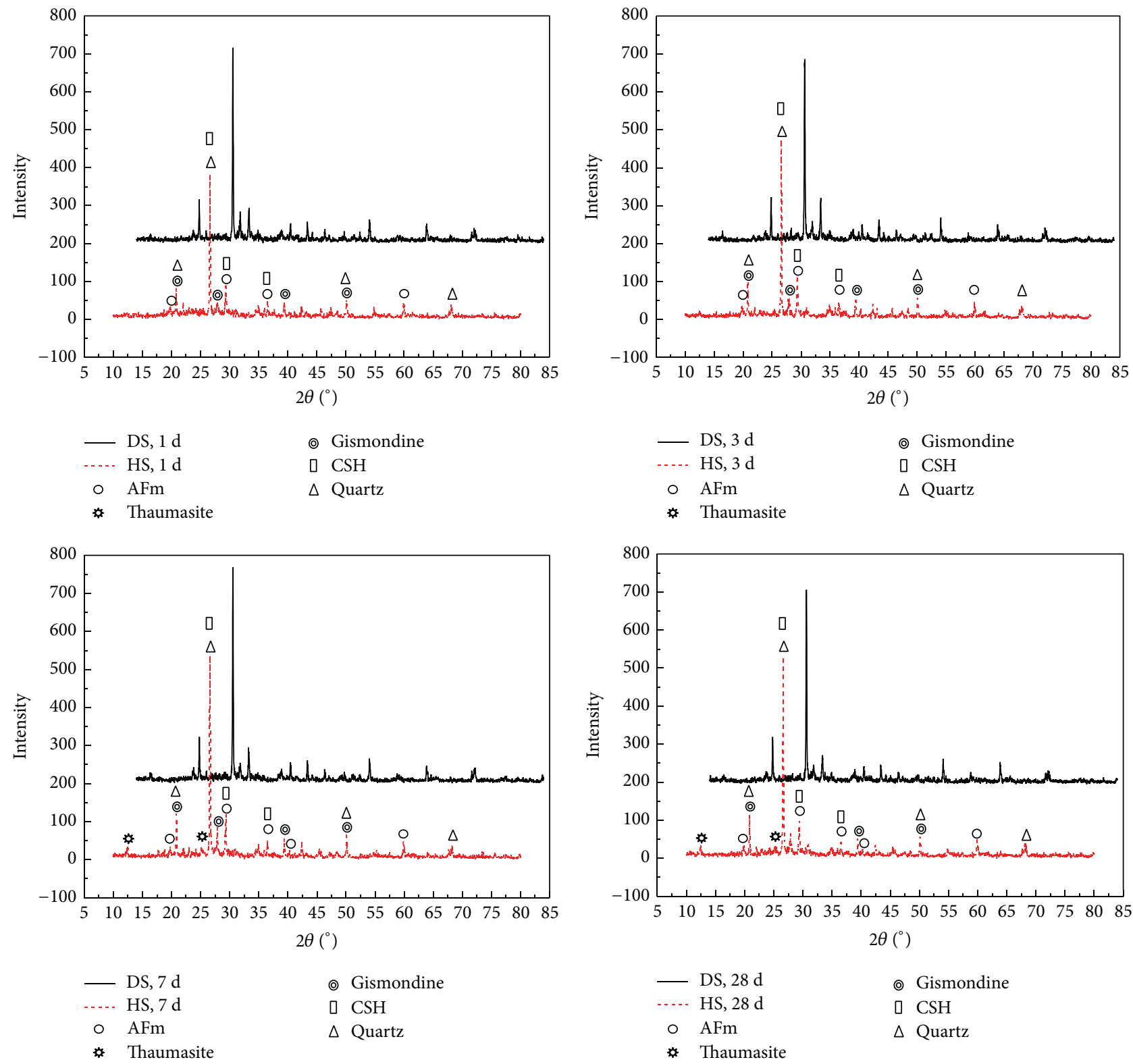

FIGURE 9: XRD curves of cemented soil with freshwater and seawater at different curing times.

$\mathrm{Al}_{2} \mathrm{O}_{3}$ in cement soil further react with low alkaline hydrated calcium silicate, producing hydrated calcium aluminosilicate. Therefore, the maximum diffraction peak decreases continuously, while the second peak is the same as the initial value due to the generation of hydrated calcium aluminosilicate, which has no significant changes. The generated low alkaline hydrated calcium silica and the crystals of gismondine have a higher density than high alkaline hydrated calcium silicate, thus improving the quality of the crystals of hydration and increasing the strength and density of cement soil. The specific reaction can be represented as follows:

$\mathrm{SiO}_{2}+x \mathrm{Ca}(\mathrm{OH})_{2}+(m-x) \mathrm{H}_{2} \mathrm{O} \longrightarrow x \mathrm{CaO} \cdot \mathrm{SiO}_{2} \cdot m \mathrm{H}_{2} \mathrm{O}$

$(x>1.5$, High alkaline hydrated calcium silicate $)$ $x \mathrm{CaO} \cdot \mathrm{SiO}_{2} \cdot m \mathrm{H}_{2} \mathrm{O}+(x-1) \mathrm{SiO}_{2}+n \mathrm{H}_{2} \mathrm{O}$

$\longrightarrow x \mathrm{CaSiO}_{3} \cdot(m+n) \mathrm{H}_{2} \mathrm{O}$

(low alkaline hydrated calcium silicate)

$$
\begin{gathered}
\mathrm{Ca}^{2+}+\mathrm{SiO}_{3}{ }^{2-}+\mathrm{SiO}_{2}+\mathrm{Al}_{2} \mathrm{O}_{3}+4 \mathrm{H}_{2} \mathrm{O} \\
\longrightarrow \mathrm{CaO} \cdot \mathrm{Al}_{2} \mathrm{O}_{3} \cdot 2 \mathrm{SiO}_{2} \cdot 4 \mathrm{H}_{2} \mathrm{O}
\end{gathered}
$$

(hydrated calcium aluminosilicate, gismondine)

4.2. Filling and Antierosion. Pozzolanic reaction is carried out in the pores of cement-stabilized soil. Some researches have shown that the small pore $(<0.1$ micron) volumes of 

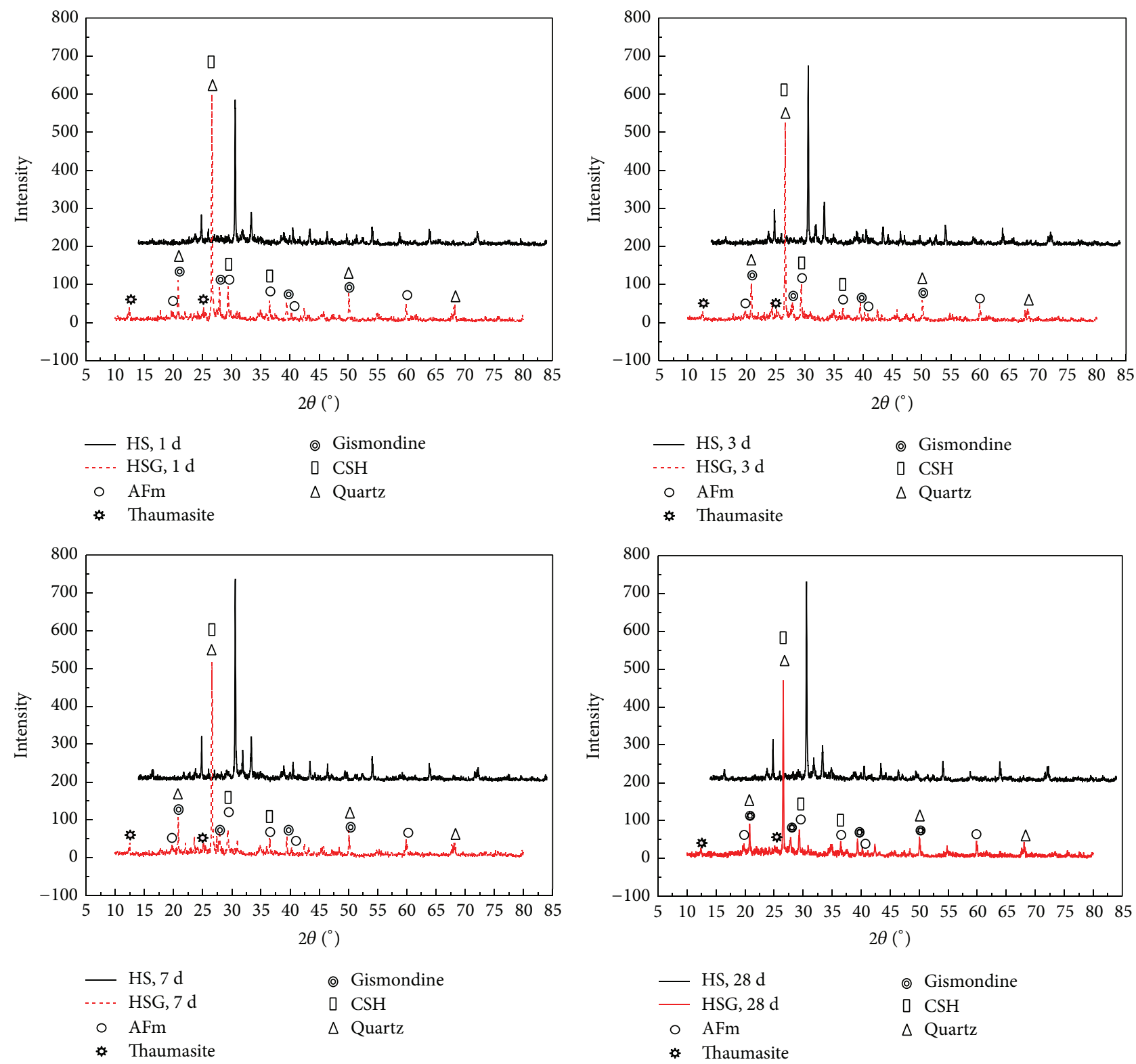

FIGURE 10: XRD curves of cemented soil with seawater blended ultrafine silica fume or not in varying ages.

the cement-stabilized clay mixed with fly ash are higher than those of the cement-stabilized clay. It implies that large pore space can be reduced due to the dispersion of claycement clusters by pozzolanic material [23]. Silica fume has the similar pozzolanic effect as fly ash, so it can also reduce the large pore space and the hydration products both filled with and split the original lager pore, reducing the porosity and improving the cementation. Then it can improve the strength and compactness. Further, comparing the XRD peaks at the 28th day of hydration produces such as gismondine and erosion products of single sulfur sulphoaluminate such as calcium sulphoaluminate (AFm) and thaumasite of cement-stabilized soil mixed with seawater adding ultrafine silica fume or not, we can find that the peaks of crystal concentrations of cement soil mixed with silica fume are lower than those without silica fume blended, showing the inhibitory effect of ultrafine silica fume, because it enables the cement soil to develop the denser structure and to prevent the infiltration of corrosive ions (e.g., $\mathrm{SO}_{4}{ }^{2-}$, and $\mathrm{Cl}^{-}$), thereby restraining the cement hydration process and AFm crystal generation in cement-stabilized soil, improving the corrosion resistance, avoiding the high expansion on account of erosion and the generation of low strength materials, and enhancing the strength while reducing swelling.

\section{Conclusions}

(1) Ultrafine silica fume can improve the strength of cementstabilized soil to some degree and inhibit the expansion at the same time. The expansion of load-free samples mixed with seawater and added with silica fume after 90 days was $55 \%$ lower than those without silica fume added and only $17 \%$ 
higher than those with freshwater. The strength is increased by $60 \%$ and $6.5 \%$, respectively, compared with the cementstabilized soil with freshwater and seawater, both without silica fume.

(2) The experimental results show that the changes are related to the crystal growth and variation. The researches of specific gravity and moisture content at different curing times show that the specific gravity of cement-stabilized soil with different ratios decreases with the curing time, which can illustrate that there are crystals generated during the hydrated process. Because of the lower specific gravity crystals, compared with cement and natural minerals of clay, the specific gravity of cement-stabilized soil decreased gradually. There is the lowest specific gravity with 2.47 of cement-stabilized soil mixed with seawater and without silica fume added at the 90th day which indicated that more crystals could be generated when there is no silica fume to be added; this is one of the reasons why the expansion was so great. As curing time increased, the water content of cement-stabilized soil also decreased and cement-stabilized soil mixed with seawater and silica fume was the highest at the 90th day, which implied that the silica fume can compact soil structure and the water is difficult to lose.

(3) From XRD experimental results, it was found that adding activated silica fume into cement-stabilized soil mixed with seawater promotes the generation of early hydration products (high alkaline calcium silicate hydrate and gismondine). As hydration continues, high alkaline hydrated calcium silicate converts into low alkaline hydrated calcium silicate with ultrafine silica fume participating in the reaction, thus improving the quality of the crystals of hydration and increasing the strength and density of cement-stabilized soil.

(4) Directly mixing seawater into cement-stabilized soil can improve the strength of the cement-stabilized soil, but the expansion will develop continuously which is harmful to the cement-stabilized soil. For this reason, in engineering applications, we cannot directly use seawater. The feasible way is adding a certain amount of ultrafine silica fume into cement curing agent to control the inflation and increase the strength.

\section{Conflict of Interests}

The authors declare that there is no conflict of interests regarding the publication of this paper.

\section{Acknowledgments}

This research was supported by Nonprofit Applied Research Project of Zhejiang Province under Grant no. 2013C33064 and Zhejiang Provincial Natural Science Foundation under Grant no. LY12E09005. The authors wish to thank Zhang Yin for his help with the use of electron scanning microscopy.

\section{References}

[1] M. Chittaranjan, T. Srikanth, B. Y. Lakshmi, and D. Pavani, "Effect of sea water on some geo technical properties of clayey soil," International Journal of Earth Sciences and Engineering, vol. 4, pp. 161-164, 2011.
[2] M. Choquette, M.-A. Bérubé, and J. Locat, "Mineralogical and microtextural changes associated with lime stabilization of marine clays from eastern Canada," Applied Clay Science, vol. 2, no. 3, pp. 215-232, 1987.

[3] J.-M. Yun, Y.-S. Song, J.-H. Lee, and T.-H. Kim, "Strength characteristics of the cement-stabilized surface layer in dredged and reclaimed marine clay, Korea," Marine Georesources and Geotechnology, vol. 24, no. 1, pp. 29-45, 2006.

[4] H. W. Xiao and F. H. Lee, "Curing time effect on behavior of cement treated marine clay," Proceedings of World Academy of Science: Engineering \& Technolog, vol. 3, pp. 155-162, 2008.

[5] L. Chen and D.-F. Lin, "Stabilization treatment of soft subgrade soil by sewage sludge ash and cement," Journal of Hazardous Materials, vol. 162, no. 1, pp. 321-327, 2009.

[6] P. Sukmak, P. D. Silva, S. Horpibulsuk, and P. Chindaprasirt, "Sulfate resistance of clay-Portland cement and clay highcalcium fly ash geopolymer," Journal of Materials in Civil Engineering, 2014.

[7] L. Wang, A. Roy, R. Tittsworth, and R. K. Seals, "Mineralogy of soil susceptible to sulfate attack after stabilization," Journal of Materials in Civil Engineering, vol. 16, no. 4, pp. 375-382, 2004.

[8] G. Rajasekaran, "Sulphate attack and ettringite formation in the lime and cement stabilized marine clays," Ocean Engineering, vol. 32, no. 8-9, pp. 1133-1159, 2005.

[9] A. J. Puppala, N. Intharasombat, and R. K. Vempati, "Experimental studies on ettringite-induced heaving in soils," Journal of Geotechnical and Geoenvironmental Engineering, vol. 131, no. 3, pp. 325-337, 2005.

[10] V. R. Ouhadi and R. N. Yong, "Ettringite formation and behaviour in clayey soils," Applied Clay Science, vol. 42, no. 12, pp. 258-265, 2008.

[11] G. Rajasekaran and S. N. Rao, "Lime migration studies in marine clays," Ocean Engineering, vol. 23, no. 4, pp. 325-355, 1996.

[12] G. Rajasekaran and S. Narasimha Rao, "Compressibility behaviour of lime-treated marine clay," Ocean Engineering, vol. 29, no. 5, pp. 545-559, 2002.

[13] S. Wild, J. M. Kinuthia, G. I. Jones, and D. D. Higgins, "Suppression of swelling associated with ettringite formation in lime stabilized sulphate bearing clay soils by partial substitution of lime with ground granulated blastfurnace slag," Engineering Geology, vol. 51, no. 4, pp. 257-277, 1999.

[14] L. Wang, A. Roy, R. K. Seals, and Z. Byerly, "Suppression of sulfate attack on a stabilized soil," Journal of the American Ceramic Society, vol. 88, no. 6, pp. 1600-1606, 2005.

[15] A. Kavak, G. Bilgen, and O. F. Capar, "Using ground granulated blast furnace slag with seawater as soil additives in lime-clay stabilization," Journal of ASTM International, vol. 8, no. 7, Article ID JAI103648, 2011.

[16] M. J. McCarthy, L. J. Csetenyi, A. Sachdeva, and R. K. Dhir, "Identifying the role of fly ash properties for minimizing sulfateheave in lime-stabilized soils," Fuel, vol. 92, no. 1, pp. 27-36, 2012.

[17] X. J. Pei and J. H. Wu, "Selection of cement additive in treating marine soft soil with DCM," Chinese Journal of Geotechnical Engineering, vol. 22, pp. 319-322, 2000 (Chinese).

[18] A.-W. Yang, D.-J. Du, R.-B. Zhao, Y.-H. Liu, and J. Liu, "Experimental study on cement and its additional agent to cure Tianjin marine soft soil," Rock and Soil Mechanics, vol. 28, no. 9, pp. 1823-1827, 2007 (Chinese).

[19] H. Xing, X. Yang, C. Xu, and G. Ye, "Strength characteristics and mechanisms of salt-rich soil-cement," Engineering Geology, vol. 103, no. 1-2, pp. 33-38, 2009. 
[20] S. Horpibulsuk, R. Rachan, A. Chinkulkijniwat, Y. Raksachon, and A. Suddeepong, "Analysis of strength development in cement-stabilized silty clay from microstructural considerations," Construction and Building Materials, vol. 24, no. 10, pp. 2011-2021, 2010.

[21] S. Horpibulsuk, R. Rachan, and A. Suddeepong, "Assessment of strength development in blended cement admixed Bangkok clay," Construction and Building Materials, vol. 25, no. 4, pp. 1521-1531, 2011.

[22] M. D. Cohen, "Theories of expansion in sulfoaluminate-type expansive cements: schools of thought," Cement and Concrete Research, vol. 13, no. 6, pp. 809-818, 1983.

[23] S. Horpibulsuk, "Strength and Microstructure of Cement Stabilized Clay, Scanning Electron Microscopy," Dr. Viacheslav Kazmiruk (Ed.), InTech, 2012, http://www.intechopen.com/ books/scanning-electron-microscopy/strength-and-microstructure-of-cementstabilized-clay. 

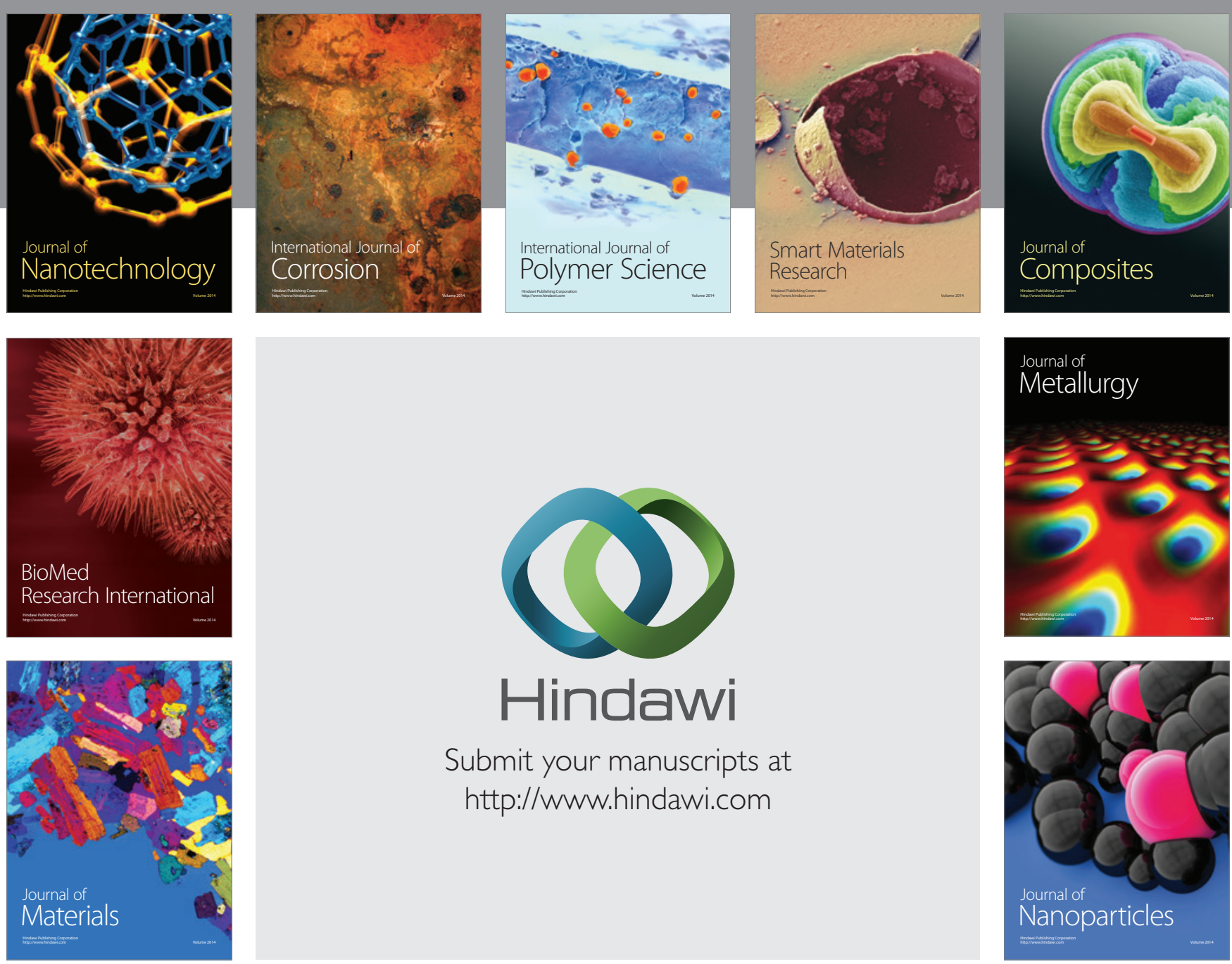

Submit your manuscripts at http://www.hindawi.com
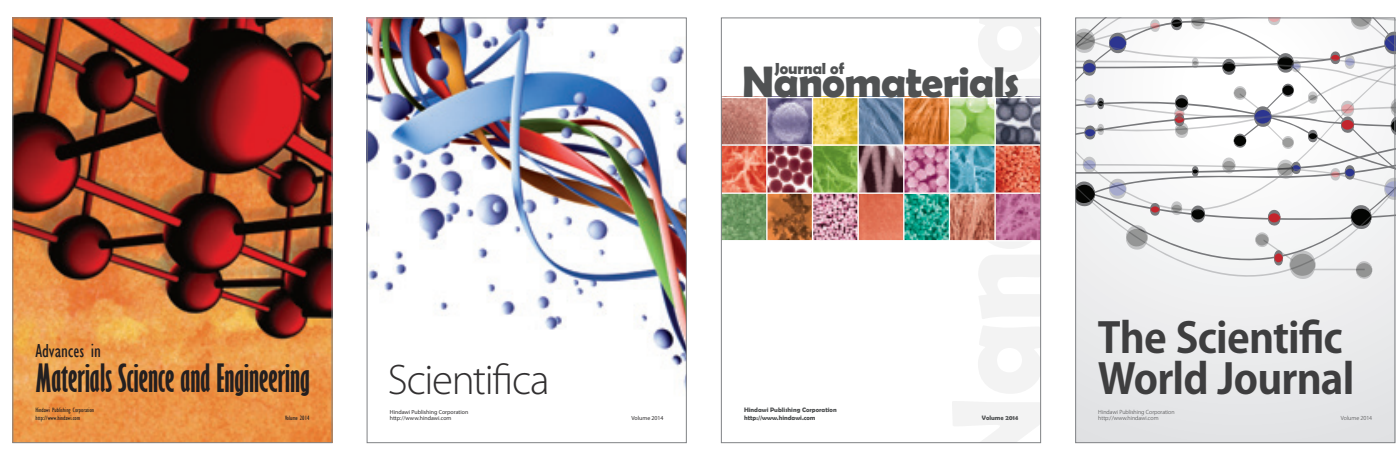

\section{The Scientific World Journal}
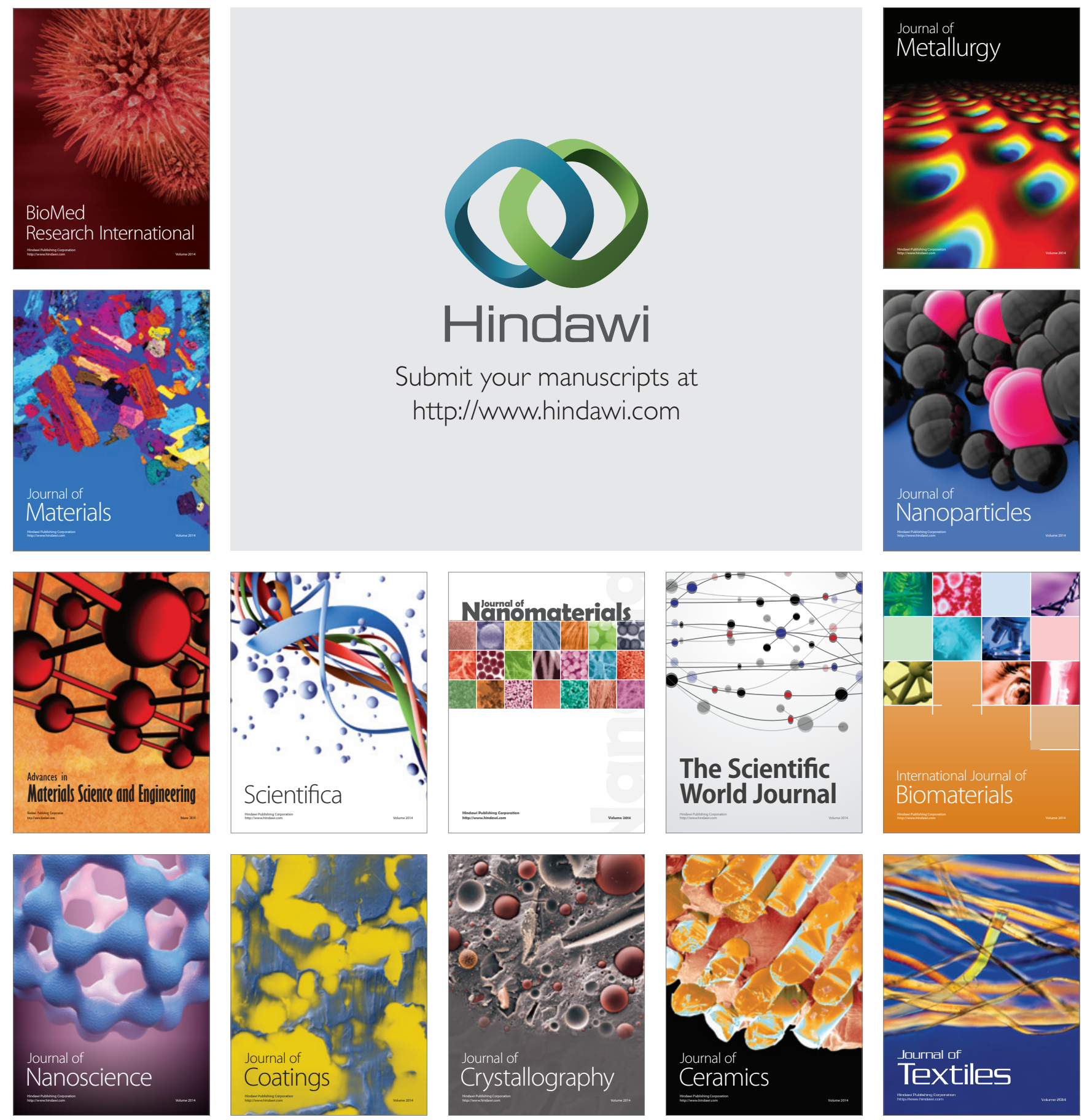